\title{
THE ECOLOGY OF EU COMPETITION LAW: A QUANTITATIVE ANALYSIS OF RULE DYNAMICS AND RULE STOCK
}

\author{
Wesley Kaufmann* and Arjen van Witteloostuijn ${ }^{* *}$
}

\begin{abstract}
Despite heated debate concerning the impact of the European Union (EU) on its member states, quantitative estimates of EU policy output remain scarce. In this study, we introduce a counting method that allows us to accurately determine the exact size of legal rules contained within EU competition law regulations. This counting method is embedded in an ecological approach, which posits that, apart from external pressures, an internal dynamic is a key driver of EU policy output. Overall, our findings indicate that the competition rule stock has increased drastically over time, and continues to do so, above and beyond the impact of external policy output drivers.
\end{abstract}

Keywords: EU competition law; rule counting method; ecology of law

\section{Introduction}

The impact of the European Union (EU) on its member states and their inhabitants has been a hotly debated topic for decades. Public opinion seems to suggest that there are too many European rules, in too many areas. As a result, the EU has been likened to an overregulating nanny state, eroding national sovereignty. ${ }^{1}$ According to Neyer, 'the legal output of the EU can easily be compared to an average nation-state and surely surpasses that of any other international organization'. ${ }^{2}$ Indeed, some scholars have suggested that, at least for certain industries, about 80 per cent of all applicable legislation in member states is now adopted at the EU level. ${ }^{3}$

Both proponents and opponents of the EU make ample use of these estimations. Proponents use such statistics to demonstrate that Europe matters, whereas opponents refer to the same numbers to support their claim that the EU threatens national sovereignty. ${ }^{4}$ Given the relevance of the Europeanisation debate, we would expect quantitative literature on EU policy output to be flourishing. This, however, is not the case, as to our knowledge there is only a handful of studies that have examined, in detail, the quantity of EU policy output, and the changes thereof over time. Alesina et al., for example, consider all EU legal acts, judiciary acts and international agreements in their analysis of EU policy-making intensity. ${ }^{5}$ Similarly, Pollack provides a count overview

\footnotetext{
Wesley Kaufmann (wesley.kaufmann@ua.ac.be) works at the Antwerp Centre of Evolutionary Demography of the University of Antwerp (Belgium).

* Arjen van Witteloostuijn (arjen.vanwitteloostuijn@ua.ac.be) works at the Antwerp Centre of Evolutionary Demography of the University of Antwerp (Belgium) and the universities of Tilburg and Utrecht (Netherlands). The authors would like to thank Thomas Möllers, the participants of the Understanding Legal Evolution Workshop of the Erasmus School of Law and an anonymous Erasmus Law Review reviewer for useful comments. Furthermore, the authors gratefully acknowledge the financial support through the Odysseus program of the Flemish Science Foundation (FWO).

J.J. Richardson, 'Policy-Making in the EU: Interests, Ideas and Garbage Cans of Primeval Soup', in J.J. Richardson (ed.), European Union: Power and Policy-Making (2006).

J. Neyer, 'Explaining the Unexpected: Efficiency and Effectiveness in European Decision-Making', 11 Journal of European Public Policy 1, at 32 (2004).

3 See G. Majone, Regulating Europe (1996), T.A. Börzel and T. Risse, 'When Europe Hits Home: Europeanization and Domestic Change', 4 European Integration Online Papers 15 (2000) and S. Hix, The Political System of the European Union (2005).

4 M. Bovens and K. Yesilkagit, 'The EU as Lawmaker: The Impact of EU Directives on National Regulation in the Netherlands', 88 Public Administration 1, at 60 (2010).

5 A. Alesina, I. Angeloni and L. Schuknecht, 'What Does the European Union Do?', 123 Public Choice 3-4, (2005).
} 
of annually adopted directives, regulations and decisions in order to study the trend of EU regulation in the post-Maastricht era. ${ }^{6}$ Finally, König et al. show the distribution of adopted legislation in their comparative study of the CELEX and Prelex databases. ${ }^{7}$

However, the abovementioned studies reach different conclusions with regard to EU policy output patterns. Whereas Pollack concludes that 'EU regulation has continued its relentless growth throughout the last four decades', ${ }^{8}$ König et al. find that 'the absolute amount of legislation passed each year has declined rapidly since the Maastricht Treaty entered into force in 1993', ${ }^{\prime}$ while the results from Alesina et al. are located somewhere in between these two extremes. ${ }^{10}$ As we will discuss in the next section, we believe that these contrasting findings can be largely attributed to database selection and sample choice issues.

Another limitation of the existing literature on EU policy output is the level of analysis. In prior work, the focus has been on the instrument level, which essentially means that each legal document of a certain type is perceived as identical. As the size of legislative documents varies considerably, this equates to a definitive simplification. Furthermore, we believe that the actual purpose of legal documents is not sufficiently taken into account in the literature. Again, the benchmark utilised by existing studies denotes the viewing of each legal document as a rule birth event, whereas, in reality, new legislation may result in either the introduction of new rules, the amendment of existing rules, the repeal of existing rules, or a combination thereof. Therefore, a more accurate counting method of EU legal rules is required.

In line with quantitative work on the evolution of organisational rules ${ }^{11}$ and the evolution of Dutch higher education law, ${ }^{12}$ we introduce a counting method that takes into account all rule birth, death and change events within a certain well-defined rule population. By determining the exact size of these events (in terms of articles, lines or words), we are able to provide an accurate estimate of an EU rule stock and its dynamics, as well as the overall effect of these dynamics on the evolution of the size of this EU rule stock. This counting method is embedded in an overarching theoretical framework called the ecology of law. ${ }^{13}$ Specifically, drawing on organisational ecology theory (a sociological perspective concerning the evolution of populations of organisations), the ecological approach argues that there is an internal, ecological dynamic that affects the evolution of any rule stock, apart from and in addition to the well-recognised external drivers of rule production.

In this study, we apply the ecological approach to one specific domain of EU policymaking, namely competition policy. Competition policy embodies one of the original objectives of the EU, and is regarded as the central means towards establishing an internal market. ${ }^{14}$ Furthermore, the field of competition policy has undergone significant modernisation in recent years, which arguably equates to the single most important

\footnotetext{
6 M.A. Pollack, 'The End of Creeping Competence? EU Policy-Making Since Maastricht', 38 Journal of Common Market Studies 3, (2000).

T. König, B. Luetgert and T. Dannwolf, 'Quantifying European Legislative Research: Using CELEX and Prelex in EU Legislative Studies’, 7 European Union Politics 4, (2006).

Pollack, above n. 6, at 536 .

König et al., above n. 7, at 559.

Alesina et al., above n. 5 .

J.G. March, M. Schulz and X. Zhou, The Dynamics of Rules: Change in Written Organizational Rules (2000), M. Schulz, 'Limits to Bureaucratic Growth: The Density Dependence of Organizational Rule Births', 43 Administrative Science Quarterly 4, (1998) and. M. Schulz, 'Impermanent Institutionalization: The Duration Dependence of Organizational Rule Changes', 12 Industrial and Corporate Change 5, (2003).

${ }_{12}$ A. van Witteloostuijn and G. de Jong, 'The Evolution of Higher Education Rules: Evidence for an Ecology of Law', 73 International Review of Administrative Sciences 2, (2007), A. van Witteloostuijn and G. de Jong, 'Changing National Rules: Theory and Evidence from the Netherlands (1960-2004)', 86 Public Administration 2, (2008) and A. van Witteloostuijn and G. de Jong, 'Ecology of National Rule Birth: A Longitudinal Study of Dutch Higher Education Law, 1960-2004', 20 Journal of Public Administration Research and Theory 1, (2010).

13 A. van Witteloostuijn, 'The Ecology of Law', 31 International Journal of the Sociology of Law 1, (2003).

${ }_{14}$ L. McGowan and S. Wilks, 'The First Supranational Policy in the European Union: Competition Policy', 28 European Journal of Political Research 2, (1995).
} 
reform in EC competition policy history. ${ }^{15}$ We expect that the extensive modernisation of this domain has significantly affected rule dynamics. This makes competition policy an ideal field in which to explore the potential of an ecology of law approach in the context of the EU.

The contribution of this study is threefold. Firstly, we aim to provide a very detailed counting method of rule birth, change and death events at the EU level. This counting method is far more accurate and informative than the counting methods used by the existing bank of quantitative legal studies (these only look at the instrument level, and for the most part assume that within the same type of instrument each legal text is identical). Secondly, we utilise a theoretical approach that aims to explain how endogenous forces intrinsic to the evolution of law influence rule dynamics at the EU level. Thirdly, whereas existing studies have mostly provided descriptive statistics regarding EU policy output, we apply the negative binomial regression method to our data (a considerably more advanced analytical tool) in order to estimate the relationships between potential drivers of rule dynamics and the key events of rule birth, change and death.

The structure of this paper is as follows. We begin by reviewing existing quantitative studies of EU policy output in Section 2. In Section 3, our ecological approach is introduced, while we explain our counting method and variables of interest in Section 4. Section 5 provides the descriptive results of our study. Section 6 contains our regression analysis, followed by a discussion section.

\section{Quantitative EU Policy Output Studies}

Aside from a number of legal Europeanisation studies that have looked at EU policy output indirectly ${ }^{16}$ we are aware of only three studies that look specifically at the EU's policy output. Firstly, Alesina et al. assess EU policy-making intensity across different policy domains, and compare actual EU policy involvement to normative criteria. ${ }^{17}$ They find that EU policy-making intensity has increased sharply over the years, but that this increase differs across policy areas. Areas that have expanded most in recent years are quite remote from the EU's original objectives, whereas other areas that would normally require a supranational approach remain at the national level.

Alesina et al.'s policy output sample consists of issued legal acts (both binding and non-binding), judiciary acts and international agreements emanating from the EU during the 1971-2000 period, including acts that are no longer in force today. ${ }^{18}$ The database used in their study is CELEX, which can be regarded as the predecessor of the current European legislation database EUR-Lex. In terms of policy output, the authors find inter alia that production of EU secondary legislation has increased three to sevenfold between the early 1970s and the late 1990s, with the bulk of this increase taking place between 1971 and 1990. However, if the data are scaled to control for the number of member states, this growth appears less impressive. In fact, with this scaled data, the authors reveal that the number of legal acts and court judgments stabilised after 1990.

Yet, Alesina et al. focus their discussion on the un-scaled data, on the grounds that EU membership is likely to lead to an underestimate of EU policy-making incidence. ${ }^{19}$ They argue that decisions and court cases are more likely to be correlated with the number of member states, whereas directives and regulations apply to the Union as a whole irrespective of the number of member states. However, the accompanying

\footnotetext{
5 See, for example, S. Wilks, 'Agency Escape: Decentralization or Dominance of the European Commission in the Modernization of Competition Policy?', 18 Governance: An International Journal of Policy, Administration, and Institutions 3, (2005).

16 Bovens and Yesilkagit, above n. 4, J.G. Christensen, 'EU Legislation and National Regulation: Uncertain Steps Towards a European Public Policy', 88 Public Administration 1, (2010) and M. Jenny and W.C. Müller, 'From the Europeanization of Lawmaking to the Europeanization of National Legal Orders: The Case of Austria', 88 Public Administration 1, (2010).

17 Alesina et al., above n. 5.

18 Id.

19 Id.
} 
descriptive output data seems to contradict this argument. ${ }^{20}$ A closer inspection of this data indicates that the number of issued directives has stabilised, whereas the number of regulations has actually decreased since the mid 1980s.

Here we see two related potential pitfalls of EU policy output analysis: using composite measures of different legal instruments in order to determine overall EU policy output patterns, on the one hand, and assigning output growth of one type of legal instrument to EU policy output as a whole, on the other hand. Based on our interpretation of Alesina et al.'s results, ${ }^{21}$ EU policy output seems to have stabilised, at least with regard to directives and regulations, a finding which is clearly not in line with public opinion. In fact, König et al. even conclude that, in absolute terms of policy output, there has been a rapid decline in adopted secondary legislation since 1993. ${ }^{22}$ Again, no distinction is made between the different types of legal instruments in this discussion of the descriptive results. In fact, the authors provide little in the way of explanation for this counter-intuitive finding of EU policy output. They too use the CELEX database in order to determine the number of adopted regulations, directives and decisions.

However, König et al.'s sample size is much smaller than the one used by Alesina et al. ${ }^{23}$ This limitation is noted by the authors themselves, who state that 'these studies illustrate the wide range of numbers cited by researchers using the same data source $[\ldots]$ In this example we predict that Alesina et al. (2005) cite sector 3 CELEX data and that their numbers may include corrigenda, Commission tertiary legislation and (possibly) duplicate cases. ${ }^{24}$ If anything, this clearly shows that sampling criteria can affect sample sizes and, ultimately, outcomes, even if the same database is used. Naturally, this problem is further exacerbated if different data sources are used.

Pollack, for example, uses the Directory of Community Legislation in Force as his data source for EU policy output. ${ }^{25} \mathrm{He}$ lists the count of annually adopted directives, regulations and decisions in force for six issue areas between 1958 and 1998. According to the author, the 1990s can be characterised as a period of political and economic backlash, caused by the rise of political anti-centralisation sentiments, German unification, EMU convergence criteria, and EU enlargement. As a result, one would expect EU policy-making retrenchment during this time period. However, Pollack offers evidence to the contrary: 'when regulations are considered alongside directives, the pace of EU regulation during the latter half of the 1990s - i.e. after the completion of most of the 1992 internal market programme - has been consistently greater than the period between the adoption of the Single Market Act and Maastricht.' ${ }^{26}$

Such a strong increase in EU policy output, although in line with public opinion, sharply contrasts with the results from the two other aforementioned output studies. When we compare Pollack's output estimates to those of the other two studies, we find a very large sample size difference. Pollack's highest count of directives and regulations together, for example, in 1993, is valued at roughly 85 acts. ${ }^{27}$ By contrast, König et al., report a count of 347 acts for the same year. ${ }^{28}$ These varying findings again demonstrate that sampling criteria, as well as data source choice, can significantly influence policy output estimates.

So, which pattern of EU policy output is closest to reality? Has EU policy output increased, decreased or stabilised over time? The fact of the matter is that, based on existing research, we simply cannot tell. Therefore, in order to better understand EU policy output dynamics, more robust and accurate counting methods are needed. We

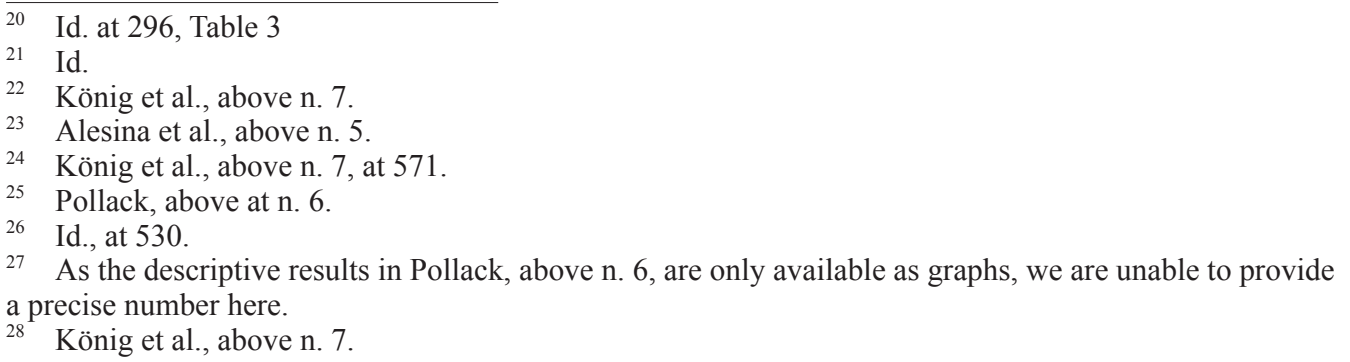


will describe such a method in detail in Section 4. However, we will first begin by introducing the ecological approach through which we will examine the evolution of EU policy output.

\section{The Ecology of Law Approach}

As outlined above, existing quantitative studies dealing with EU rule dynamics have focused on the relationship between, and the role of, EU institutions with regard to policy-making output. The aim in this paper is to show that, apart from institutional settings and external pressures, there is also an internal ecological dynamic that drives the EU rule stock. This so-called ecology of law approach draws on organisational ecology theory. ${ }^{29}$ From this perspective, legal rules are viewed as populations of social entities, not unlike animals or organisations. These rule populations are thus determined by 'population-specific ecological processes and by the path-dependent dynamic of these processes'. ${ }^{30}$

Central to the ecology of law approach is organisational ecology's density dependence theory. This is concerned with the effect of density, which encompasses the count of entities in a certain population, on the vital rates (birth, death, and change events) of that population. With regard to organisations, many studies have provided support for, on the one hand, a hill-shaped relationship between population density and founding (birth or entry) rates and, on the other hand, a U-shaped relationship between population density and mortality (death or exit) rates.

These (inverse) U-shaped relationships are the result of competition and legitimation processes, which have opposite effects on birth and death rates. For birth rates, the process of competition is predicted to result in a negative density dependence relationship. For organisations, the argument follows that with more organisations in the market, the lower the entry rates, due to competition. By contrast, the legitimation process suggests a positive density dependence relationship, as the societal acceptance of the economic or social activity increases when an organisational form associated with this activity is observed more frequently. If the competition and legitimation processes are combined, we arrive at a hill-shaped relationship for birth rates and density. With regard to mortality rates, legitimacy is argued to increase with density, thus lowering mortality rates (negative density dependence). As density increases, however, so does competition intensity, which will raise mortality rates (positive density dependence). If both processes are taken together, we arrive at a U-shaped relationship for mortality rates and density. This density-dependent organisational mortality pattern is confirmed by Hannan and Freeman in their study of American labor unions during the period 1836-1985 (one of many examples). ${ }^{31}$

In the ecology of law context, the legitimation process can be interpreted as supporting a Weberian and post-Weberian argument that rules breed rules, whereas the competition process is linked to learning theory. ${ }^{32}$ The rules breed rules argument purports that public administration gains legitimation by applying and producing legal rules. With increasing societal complexity, a parallel demand for new legal rules emerges. As the introduction of new rules may itself introduce new issues, which need to be resolved through the introduction of yet a new set of rules, the rule stock seems to expand almost of its own accord. ${ }^{33}$ In contrast, learning theory would suggest that rulemaking bodies learn continuously, thus reducing the need for new rules. There are (at least) four drivers that therefore have a dampening effect upon rule production: problem

\footnotetext{
29 Van Witteloostuijn, above n. 13.

30 Van Witteloostuijn and de Jong (2010), above n. 12, at 193.

31 M.T. Hannan and J. Freeman, 'The Ecology of Organizational Mortality: American Labor Unions, 1836-1985', 94 American Journal of Sociology 1, (1988) and see G.R. Carroll and M.T. Hannan, The Demography of Corporations and Industries (2000).

32 Van Witteloostuijn, above n. 13.

33 Van Witteloostuijn and de Jong (2010), above n. 12, at 194.
} 
availability is reduced over time, the application range of existing rules is expanded over time, ineffective rules are abolished along the way, and more specific and separate rules may be combined into more general and integrative rules. ${ }^{34}$

If we apply this logic to rule birth rates, the combined effect of the rule-breeding and learning processes results in the now familiar hill-shaped relationship between rule birth and density, a pattern confirmed by van Witteloostuijn and de Jong in their study of national rule birth in the Dutch higher education domain between 1960 and $2004 .^{35}$ For rule death rates, the story is the opposite, which lends itself to the prediction of a U-shaped density relationship (mentioned but not tested by van Witteloostuijn and de Jong). ${ }^{36}$

In the context of the European Union, our aim is to determine whether internal rule dynamics are at work, above and beyond what one would expect based on increasing complexity. Over time, the EU has not only expanded from six to twenty-seven member states, but has also increased the breadth and depth of its policy involvement. As a result, an increase in policy output over time is to be expected. However, if (post-)Weberian processes are at work, EU policy output may have increased more than we would expect based solely on complexity issues. This line of reasoning resembles the often-expressed complaint that the EU has gone too far, and is now too deeply involved in matters that are best left to the individual member states.

Apart from (inverse) U-shaped density dependence relationships, we also posit that there will be a direct positive correlation between rule death and birth events, and vice versa. This hypothesis is based on the relationship between organisational rules and the associated problem space, as outlined by March et al. ${ }^{37}$ The argument here is that rules are introduced in response to environmental problems and pressures, albeit mediated by the prevailing rule stock. If existing rules are suspended, the problem space expands and opportunities for the introduction of new rules arise. Similarly, if there is much rule birth activity, the problem space will be (largely) occupied. With more rules in place, we argue that rule death rates are also expected to increase for a couple of reasons. Firstly, the probability of a rule death event will be higher if the population at risk is larger. Secondly, if the problem space is crowded, rule-makers wishing to introduce new rules will first need to repeal (some) existing rules.

There is also an administrative argument for expecting a positive relationship between rule death and birth events. As many new laws repeal existing rules and introduce new rules at the same time, both rule birth and rule death events are combined into one time slot. Hence, although the size effect of rule birth and death events may differ significantly, the timing of many of these events may correspond perfectly.

The third type of event is rule change. Indeed, in law-making practice, existing law is amended all the time. ${ }^{38}$ However, as there are no theoretical predictions concerning the direction and shape of the relationship between rule density and rule change events, we only provide descriptive results of rule change events in Section 5.

\section{Data Collection and Measurement}

\subsection{Collecting the Data}

All legal acts that have been published in the Official Journal of the European Union can be retrieved online through the EUR-Lex database, which contains over two million legal texts. Essentially, there are three types of binding legal instruments at the EU level: Regulations, directives and decisions. In the context of the current study, we are interested purely in regulations in the competition law domain. Decisions are excluded, as they are only binding vis-à-vis the parties addressed, and do not apply to the EU as

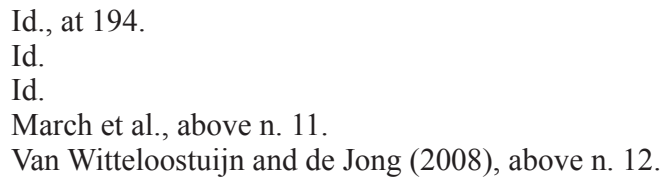


a whole. Directives are also not taken on board, since they need to be transposed into national legislation, and are, by their very nature, only binding with regard to their specified results. This means that the actual legal text, which constitutes the core of our analysis, cannot be measured objectively from a counting point of view, given the fact that the text of a directive is essentially an intermediate, as opposed to the finished, product. For the same reason, this study does not take into account non-binding legal instruments, such as recommendations and opinions. Since regulations are fully binding in their entirety upon all member states, and are a finished product in terms of legal rule size, they are particularly well suited for a count analysis, and can objectively be compared over time.

In order to retrieve the relevant competition law regulations, we use the 'directory code' and 'form' search criteria, incorporated in the advanced search module of EURLex. The directory code criterion provides a classification of the twenty EU law domains (i.e., competition law, agriculture, and external relations). These directory codes are further divided into sub-categories; there are eighteen such categories in the competition law domain, all of which are included in our sample. At the same time, the form criterion allows us to retrieve regulations only, and to ignore other legal instruments. After excluding regulation proposals, we are left with 128 unique regulations. For each of these regulations, we download the English text in rtf-format from EUR-Lex, and subsequently copy-and-paste each regulation into a separate Microsoft Word-document. ${ }^{39}$ In addition to the complete legal text and certain biographical details (i.e. entry into force date, and directory code), EUR-Lex also provides amendment information under the headings 'amended by' and 'amendment to'. This information, which will be later used in order to accurately count legal rules, is also included for each regulation, if applicable.

Given the importance of our data collection procedure, we decided to perform an additional robustness check in order to assure the comprehensiveness of our sample. Firstly, we retrieved an overview of all legislative acts currently in force in the competition policy domain from EUR-Lex. This overview not only contains information on competition law regulations, but also concerning other legal instruments. We filtered out the information on regulations, and for each of these used EUR-Lex to trace any amendments or repeals made to previous regulations that are no longer in force. We repeated this process of backward tracking until we were left with 71 unique regulations. All of these regulations were already included in our final sample. The difference between the 128 regulations of our final sample and the 71 regulations subject to our robustness check sample is solely that the latter are neither explicitly linked to any regulation(s) currently in force, nor are they in force today. The outcome of our robustness check, combined with the fact that EUR-Lex claims to provide complete records of all legislative acts published in the Official Journal since 1957, instills confidence that our final sample is complete. In fact, since we have now retrieved all competition law regulations during the 1962-2008 period, our final sample contains the entirety of competition rules that are translated into regulations.

\subsection{Counting EU Competition Rules}

Most quantitative EU legal studies use counts of policy acts in order to derive simple statistical information. The main advantage of this approach is its transparent and objective nature, while its biggest drawback lies in the fact that a simple counting measure does not tell us anything about the actual impact of an individual policy act. ${ }^{40}$ However, Alesina et al. argue that this problem is mitigated if sample sizes are sufficiently large. ${ }^{41}$ Nonetheless, in our view, existing counting methods can be improved upon. First and foremost, the unit of analysis in the literature is the legal instrument, which essentially means that each legal instrument is assigned the exact same value. This is a

\footnotetext{
For one regulation, namely Regulation 153/1962, only a Dutch tiff-format was available online. In this case, the word and line count, as outlined below, was performed manually.

${ }_{40}$ Alesina et al., above n. 5, at 279-280.

41 Id.
} 
great simplification, as the size and purpose of legal instruments will vary greatly, not only between different types of instruments (i.e. regulations vis-à-vis directives), but also within the same type of instrument.

If we take the competition law domain as an example, we see that between 1962 and 2008 the smallest regulation consisted of only one article, while the largest regulation consisted of forty-five. The existing quantitative studies would either ignore the onearticle regulation as being trivial (which might indeed be the case), or count both regulations as ' 1 ', which is clearly inaccurate in such a case. Obviously, there is a whole spectrum of different sizes between these two extreme values.

A second limitation of many existing counting methods is the fact that they do not take into account the relationship between new and existing legal documents. Although some studies attempt to distinguish between new policy acts and amendment acts, most studies again simply count each instrument as ' 1 ', irrespective of whether a new policy act introduces new rules, amends existing ones, or repeals existing ones. We posit that in order to better understand rule dynamics, it is essential to take a closer look at the actual size effect of individual policy acts. Our counting method takes explicit note of different policy act sizes.

Specifically, taking the complete population of competition law regulations from 1962 to 2008, we use three levels of analysis to count the number of legal rules: the word, line and article level. The Word Count option in Microsoft Word is used to determine the exact number of words and lines in the main part of the legal text (preambles and appendices are not included in the analysis), while the number of articles is determined manually. All regulations have the same font (Tahoma) and font size (10). In the few instances where the layout of a specific regulation differs slightly from the benchmark, this is corrected manually. As our analysis will focus on the lowest level of analysis, namely words, comparability issues are minimal.

In line with van Witteloostuijn and de Jong, ${ }^{42}$ we make a distinction between three different event categories: rule birth, rule change and rule death. Rule birth is defined as the introduction of new legal rules into the competition law domain that have no direct link to any existing regulation. In cases where newly introduced regulations are a composite of rule birth, change and death events, only those parts of the regulation introducing new rules (as opposed to the entire regulation size) are classified as rule birth events. Rule birth events, by their very nature, always result in an increase in the number of legal rules. Rule change events refer to cases where existing legal rules are somehow amended. In line with the EUR-Lex classification, there are five different types of rule change in our sample: addition (30 events), deletion (20 events), insertion (22 events), replacement (127 events) and substitution (11 events).

We are not primarily concerned with the type of change, but in the size effect of these changes. The size effect of a rule change event can result in either an increase or a decrease in the number of legal rules, or it can be neutral. Since neutral change events do not affect the rule stock size, these events are excluded from our final analysis. This means that we work with two separate groups of rule change: rule increase changes and rule decrease changes. There are 110 rule increase change, 51 rule decrease change and 49 neutral change events in our sample.

A final remark relates to the fact that rule changes never occur at the article level. Additions, for example, either consist of new words / lines being added to an existing article, or the introduction of a new sub-article. In both cases, the net effect on the total number of articles is equal to zero. Likewise, deletions only remove part of existing articles: in these cases, where an entire article is deleted, we follow the EUR-Lex classification of rule repeal. Rule repeal events deal with the death of existing legal rules. These can occur both at the article and the regulation level. At the regulation level, we distinguish between two categories of repeal: repeal by means of a new regulation (coined sequential repeal) and sunset clauses contained in the regulation itself (labeled inherent repeal). Whereas inherent repeals are stand-alone events that reduce the rule stock, sequential repeals involve new regulations that not only repeal existing legal rules, but at the same time introduce new rules in order to replace the repealed rules. In

$\overline{42}$ Van Witteloostuijn and de Jong (2010), above n. 12. 
a sense, these sequential rule deaths are not unlike rule change. We would have liked to perform separate analyses for both types of rule death events, but the total amount of 58 rule death events (which is reduced further by aggregating the data) is simply too small to take this difference into account. Consequently, we decided to group both categories of rule death events together in our analysis.

All rule birth, change and death events are aggregated into quarterly observations. For presentation purposes, this file is further aggregated into annual observations in Section 5. As the correlation between the size measures in terms of articles, lines and words is very high for rule birth and rule death events $(>0.92)$, we use the lowest unit of analysis, which is words, in our analysis. We will now proceed to a brief descriptive analysis of the rule birth, rule death and rule change events, as well as the pattern of the rule stock evolution, before moving on to a negative binomial regression analysis in Section 6.

\section{Descriptive Results}

We start our analysis by looking at the introduction of new rules into the competition law domain: rule birth events. Following the introduction of the first competition law regulation in 1962, very little rule birth activity can be observed up to the mid-1980s. In fact, between 1963 and 1984, there are fifteen annual observations without any rule birth activity whatsoever. Furthermore, the rule birth events that do occur during this time period have a rather modest size compared to the post-1984 period.

The finding that new competition rules were introduced mainly after 1984 is in line with expectations. For example, McGowan and Wilks mention that competition policy became salient in the 1980s, which is reflected 'in the expansion and flourishing of competition law' ${ }^{43}$ Indeed, our data shows that from 1985 onwards there is considerably more rule birth activity compared to the preceding period. In fact, between 1985 and 2008 , at least one competition law regulation is introduced annually, with a clear peak of newly introduced rules in the year 2004, following the invasive modernisation of EU competition policy. Perhaps as a result of the competition policy overhaul, rule birth activity is seen as very low in 2005 , yet increases again drastically in the most recent years of our observation period.

Although rule birth activity only took off in the second part of the 1980s, noticeable rule death activity took even longer to materialise. However, there has been consistently more rule death activity since 1991, with a clear peak of rule death events in 2004. This peak is identical to the one we witnessed earlier for rule birth events, and can also be attributed to the modernisation of EU competition policy. In terms of size, rule death events are considerably smaller than rule birth events, indicating that the competition rule stock has increased over time. The evolution of rule birth and death events is illustrated in Figure 1.

The final piece of the rule dynamics puzzle involves rule change. The story for rule change events is surprisingly similar to that of rule death events, in the sense that both essentially took off in the 1990s. In fact, during the 1963-1990 period, there are only eight rule increase and two rule decrease change events. However, unlike rule birth and death events, rule change activity appears to be much more erratic. There are, for example, no rule increase or decrease events at all during the 2000-2003 period. However, we do find the now familiar peak of activity in 2004 for both types of change. Size-wise, rule change events are very small indeed, compared to rule birth and death events. In fact, the combined size of all rule increase and decrease events in our sample is equal to 8,547 words, whereas the combined size of rule birth events is equal to 219,970 words. Finally, the size of rule increase changes is roughly seven times larger than that of rule decrease changes, which means that on the whole rule change events result in an increase of the competition rule stock.

43 McGowan and Wilks, above n. 18, at 151. 
Figure 1 The evolution of EU competition rule births and deaths

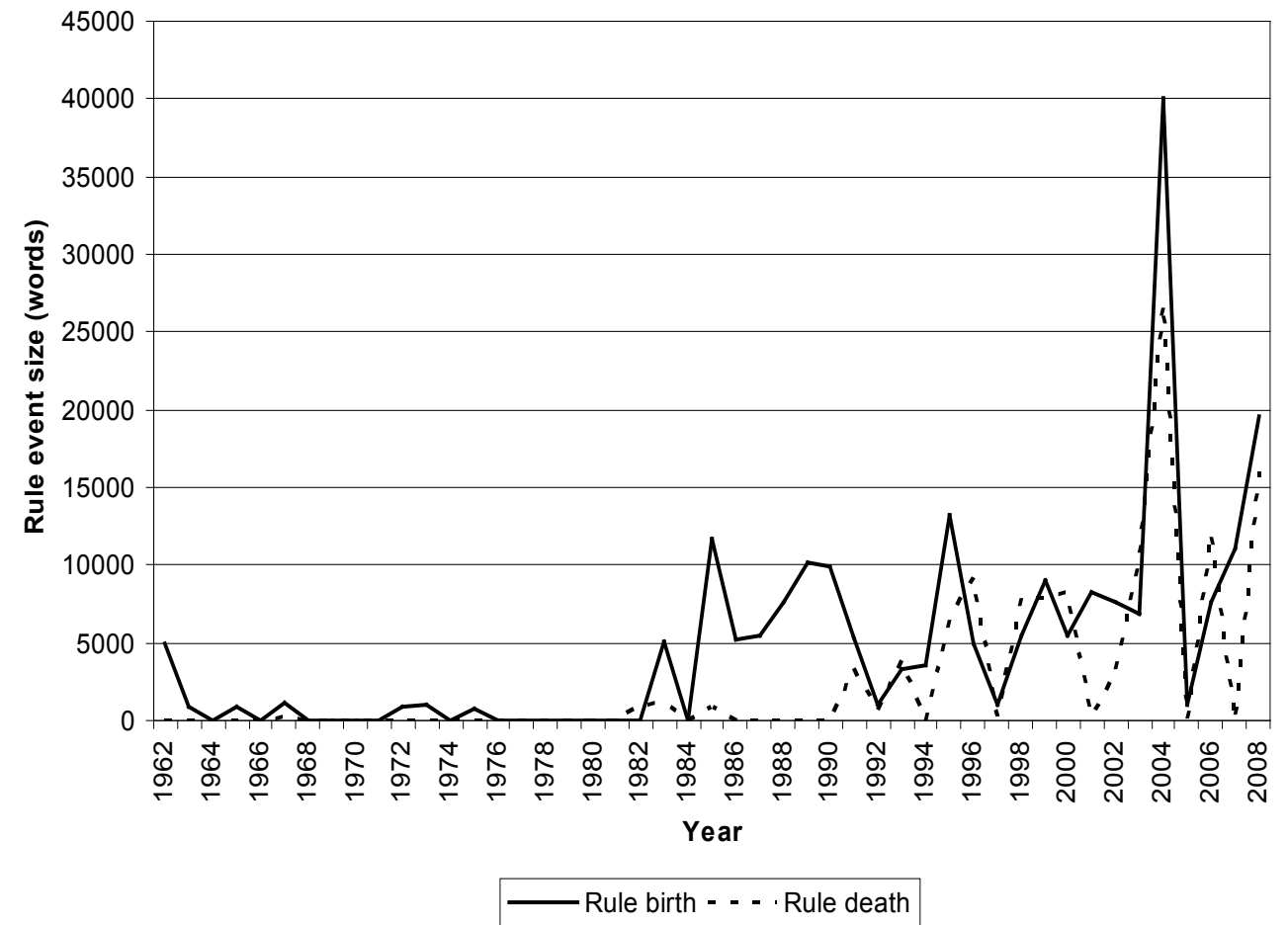

The next step is to combine the information on rule birth, death and change events, and to determine what the net effect of these events has been on the stock of competition rules. The net mutation is defined as the balance of rule births, plus rule increase changes, minus rule decrease changes, and minus rule repeals. As shown in Figure 2, the cumulative stock in any year is therefore the volume in the previous year corrected for net mutations.

Figure 2 The evolution of the European competition rule stock

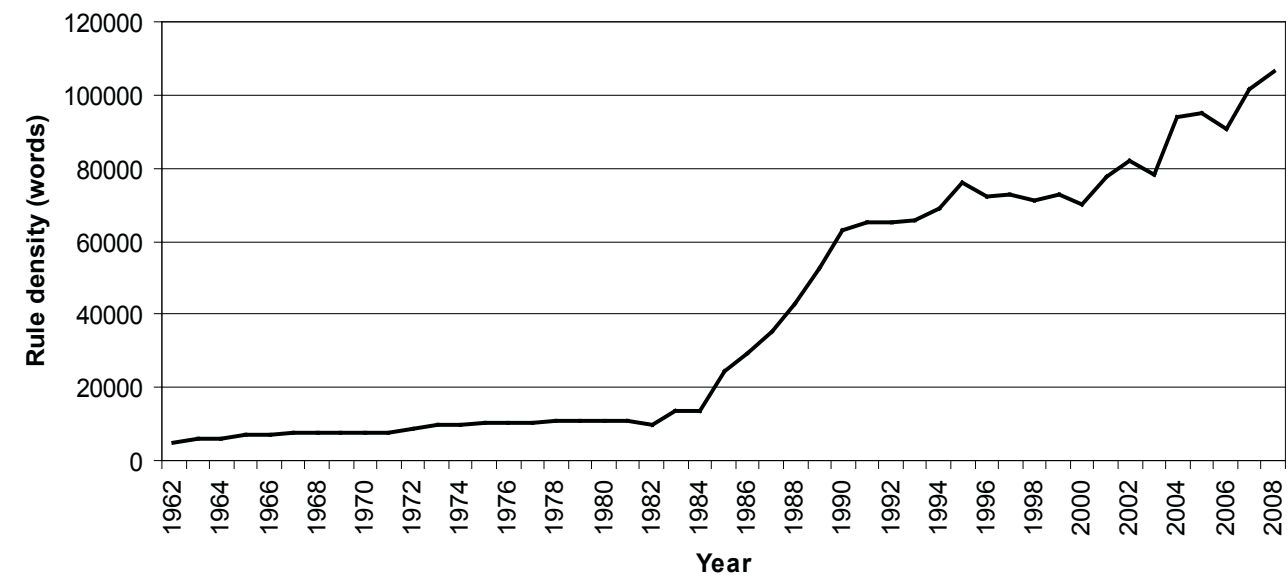

The stock of competition rules has remained more or less constant between 1962 and 1984, which is unsurprising given the general lack of rule dynamics during this period. After 1984, however, there is a very strong increase in the number of competition rules which appears to continue into the present day. The growth rate of the rule stock in terms of word size is explosive, as it doubled in size between 1984 and 1986, and increased 
to fourfold the 1984 stock equivalent by 1990 . At the end of 2008, the competition rule stock was almost eight times larger than in 1984. Consequently, competition law offers a clear example of extensive EU rule-breeding. A somewhat surprising finding is the fact that the modernisation package has not altered this trend of competition rule stock increase. Despite significant rule death activity, the amount of newly introduced rules exceeded the amount of repealed rules in the year 2004, further expanding the competition rule stock. Although the rule stock remained more or less stable in 2005 and 2006, it increased again in 2007 and 2008.

\section{Multivariate Analysis}

The next step is to analyse whether these rule dynamics events can be explained by the density dependence hypotheses implied by our ecology of law approach. For this, we require a multivariate analysis. In this section, we will test our density dependence hypotheses as outlined in Section 3 by running negative binomial regressions on our data, with rule birth and rule death events as the dependent variable. Before presenting our results, we will first discuss our choice of variables and regression method.

\subsection{Variables}

The dependent variables are the two main rule dynamics events: rule birth and rule death. As mentioned earlier, we do not have any theoretical predictions with regard to the relationship between rule change and rule density. Furthermore, the size and number of rule change observations is very small compared to rule birth and death events, which is why rule increase change and rule decrease change are included only as control variables. ${ }^{44}$ As we hypothesise a strong positive relationship between rule birth and rule death, and vice versa, the first independent variables are rule death (in the rule birth analysis) and rule birth (in the rule death analysis). The other independent variables are rule density (which is the rule stock) and rule density squared (to test for the hypothesised non-linear (reversed) U-shaped relationships).

Finally, we include three additional variables to control for external causes of EU competition rule stock increases. Firstly, we need to take into account the increase in EU member states over time. The most straightforward way of controlling for EU enlargement is to include a variable with the number of member states. However, since the correlation between the number of member states and our density variables is very high, we run the risk of encountering multicollinearity issues. Therefore, we also run our analyses with an EU enlargement dummy, which has a value of 1 for one year following the entry of new member states, and a value of 0 otherwise.

Secondly, we include another dummy variable to take into account major EU treaty revisions. This EU treaty variable has a value of 1 for one year following the entry into force of the Single European Act, the Maastricht Treaty, the Treaty of Amsterdam, and the Treaty of Nice, and a value of 0 otherwise.

Thirdly, we control for the role of Court activity in driving competition rule dynamics ${ }^{45}$ by including a variable that takes into account the number of competition policy judgments by the court of First Instance and the European Court of Justice. For the 1998-2008 period, this information is available from the European Court of Justice's Curia website, which contains all Community rulings during that time period. For the 1962-1997 period, we use the annual Reports on Competition Policy, provided by the Directorate General for Competition, in which all competition policy related rulings are also listed.

Since we have no a priori theoretical indication regarding the lag structure of our independent variables, we decided to test our models with different lags. For example,

\footnotetext{
44 We also used a composite measure of rule birth and rule death in our analyses, grouping rule birth and rule increase change together, as well as rule death and rule decrease change. However, results in this case are similar to the results reported below (available upon request from the authors).

45 McGowan and Wilks, above n. 14, Wilks, above n. 15.
} 
our density dependence results for rule birth events are qualitatively similar for up to sixteen quarterly lags (results are available from the authors upon request). For the court activity control variable, the outcome is different, as legislative changes following a court ruling are expected to take some time. Upon closer inspection, our data indicates that the court rulings variable is significant in the rule birth analyses when we use a lag specification of one year. As a result, the court rulings variable is lagged by this time period.

\subsection{Negative Binomial Regression}

The baseline model for studying change or exit events is the Poisson specification, but this specification implies the assumption that the mean of the time series equals the variance. In our sample, the variance greatly exceeds the mean, which implies that our data exhibits over-dispersion. The negative binomial regression specification generalises the Poisson model by introducing an individual unobserved effect into the conditional mean, allowing for over-dispersion in the data. Negative binomial regression has also been used in order to analyse the impact of EU presidency on legislative activity, ${ }^{46}$ implementation infringements in the $\mathrm{EU}^{47}$ and the ecology of Dutch higher education law $^{48}$ (to name just a few examples). As we cannot assume our observations to be independent, we use robust standard errors in our analysis. Our time interval is quarterly for the period from 1962 to 2008, which results in 188 time spells. In the final model specifications, we are left with 184 time spells, as the court activity control variable is lagged by four quarters. The other variables are not lagged, which does not affect the main findings, as is clear from the results of the robustness analyses reported below. All models were estimated using the NBREG routine in Stata 10.

\subsection{Empirical results}

Table 1 shows the descriptives and the correlations of our variables.

Table 1 Descriptive statistics

\begin{tabular}{|l|l|l|l|l|l|l|l|l|l|l|l|l|}
\hline Measures & Mean & S.D. & 1 & 2 & 3 & 4 & 5 & 6 & 7 & 8 & 9 & 10 \\
\hline 1. Rule birth & 1168.36 & 2974.66 & 1 & & & & & & & & & \\
\hline 2. Rule death & 652.83 & 2172.65 & $0.57^{*}$ & 1 & & & & & & & & \\
\hline 3. Rule increase change & 39.73 & 202.10 & $0.52^{*}$ & $0.29^{*}$ & 1 & & & & & & & \\
\hline 4. Rule decrease change & 5.84 & 29.65 & $0.16^{*}$ & $0.34^{*}$ & $0.24^{*}$ & 1 & & & & & & \\
\hline 5. EU enlargement & 0.13 & 0.34 & $0.23^{*}$ & 0.13 & $0.16^{*}$ & 0.03 & 1 & & & & & \\
\hline 6. EU member states & 12.04 & 5.71 & $0.39^{*}$ & $0.40^{*}$ & $0.27^{*}$ & $0.19^{*}$ & $0.29^{*}$ & 1 & & & & \\
\hline 7. EU treaty & 0.09 & 0.28 & 0.05 & 0.08 & -0.01 & 0.04 & -0.12 & 0.08 & 1 & & & \\
\hline 8. Court activity (lagged) & 5.17 & 6.82 & $0.34^{*}$ & $0.27^{*}$ & 0.11 & $0.22^{*}$ & 0.13 & $0.66^{*}$ & $0.15^{*}$ & 1 & & \\
\hline 9. Rule density & 40473.58 & 33702.21 & $0.36^{*}$ & $0.36^{*}$ & $0.25^{*}$ & $0.22^{*}$ & $0.14^{*}$ & $0.88^{*}$ & $0.23^{*}$ & $0.71^{*}$ & 1 & \\
\hline 10. Rule density squared & $2.77 \mathrm{e}+09$ & $3.24 \mathrm{e}+09$ & $0.37^{*}$ & $0.37^{*}$ & $0.27^{*}$ & $0.22^{*}$ & $0.16^{*}$ & $0.93^{*}$ & $0.17^{*}$ & $0.72^{*}$ & $0.98^{*}$ & 1 \\
\hline
\end{tabular}

The correlation coefficient between rule density and rule density squared is above the common threshold value for multicollinearity of 0.80 ; however, this is by construction - that is, both have to be included to estimate potentially non-monotonic shapes of

\footnotetext{
46 A. Warntjen, 'Steering the Union: The Impact of the EU Presidency on Legislative Activity in the Council', 45 Journal of Common Market Studies 5, (2007).

47 H.A.D. Mbaye, 'Why National States Comply with Supranational Law: Explaining Implementation Infringements in the European Union', 2 European Union Politics 3, (2001).

48 Van Witteloostuijn and de Jong (2010), above n. 12.
} 
relationships. Furthermore, although, as discussed earlier, the EU member states variable is highly correlated with our density measures, this is taken into account by substituting the member states variable with the EU enlargement dummy in our analyses. The correlation between the density measures and court rulings activity variable is also high (at 0.71 and 0.72 , respectively); however, results are similar when the court rulings variable is excluded from the analysis (results are available from the authors upon request). Finally, the correlation between rule birth and rule death events is positive, as is the correlation between rule birth and rule death, on the one hand, and our density measures, on the other hand. These positively significant correlations are in line with our hypotheses.

We estimate six regression models for the rule birth and rule death analyses; in the first three Models 1 to 3, we include the EU enlargement dummy as a control variable; in Models 4 to 6, we include the EU member states variable instead. In our baseline Models 1 and 4, only the control variables are included. In Models 2 and 5, we introduce our first independent variable: rule birth or rule death, depending on the analysis. In the full Models 3 and 6, the rule density variables are added. The various fit parameters show that our full models fit the data better than our baseline models (for example, the LR statistic is much higher for the full model estimations). As the results across the six models are consistent for the rule birth and rule death analyses, we focus our discussion on the Model 6 results. For presentation purposes, all rule count variables are divided by 1,000 in Tables 2 and 3. Table 2 provides the regression results for rule birth events.

Table 2 Regression results for rule birth events

\begin{tabular}{|l|l|l|l|l|l|l|}
\hline Measures & Model 1 & Model 2 & Model 3 & Model 4 & Model 5 & Model 6 \\
\hline Rule increase change & $1.52^{* * *}$ & $1.84^{*}$ & $2.26^{* *}$ & $1.36^{*}$ & 1.65 & $2.14^{* *}$ \\
\hline (variable divided by 1,000) & $(0.43)$ & $(0.95)$ & $(1.01)$ & $(0.73)$ & $(1.13)$ & $(0.94)$ \\
\hline Rule decrease change & 1.13 & -7.48 & $-10.13^{* *}$ & -2.88 & -7.72 & $-9.30^{*}$ \\
\hline (variable divided by 1,000) & $(5.71)$ & $(6.26)$ & $(5.09)$ & $(5.23)$ & $(7.00)$ & $(4.68)$ \\
\hline EU enlargement & $0.93^{* *}$ & 0.60 & $0.85^{*}$ & & & \\
\hline & $(0.42)$ & $(0.42)$ & $(0.47)$ & & & \\
\hline EU member states & & & & $0.15^{* * *}$ & $0.11^{* *}$ & $0.15^{*}$ \\
\hline & & & & $(0.05)$ & $(0.05)$ & $(0.09)$ \\
\hline EU treaty & $0.80^{*}$ & $0.91^{*}$ & 0.26 & 0.66 & $0.79 *$ & 0.19 \\
\hline & $(0.48)$ & $(0.48)$ & $(0.48)$ & $(0.44)$ & $(0.45)$ & $(0.41)$ \\
\hline Court activity (lagged) & $0.11^{* * *}$ & $0.09^{* * *}$ & $0.06^{* *}$ & $0.05^{* *}$ & $0.05^{* * *}$ & $0.05^{* *}$ \\
\hline & $(0.03)$ & $(0.03)$ & $(0.03)$ & $(0.02)$ & $(0.02)$ & $(0.02)$ \\
\hline Rule death & & $0.17^{* * *}$ & $0.16^{* * *}$ & & $0.14^{* *}$ & $0.14^{* * *}$ \\
\hline (variable divided by 1,000) & & $(0.06)$ & $(0.05)$ & & $(0.07)$ & $(0.04)$ \\
\hline Rule density & & & $0.11^{* * *}$ & & & $0.11^{* * *}$ \\
\hline (variable divided by 1,000) & & & $(0.03)$ & & & $(0.03)$ \\
\hline Rule density squared & & & $-9.57 \mathrm{e}-7^{* * *}$ & & & $-1.16 \mathrm{e}-6^{* * * *}$ \\
\hline (variable divided by 1,000) & & & $(2.53 \mathrm{e}-7)$ & & & $(3.31 \mathrm{e}-7)$ \\
\hline Constant & $5.75^{* * *}$ & $5.76^{* * *}$ & $3.84^{* * *}$ & $4.36^{* * *}$ & $4.73^{* * *}$ & $2.69^{* * *}$ \\
\hline & $(0.31)$ & $(0.30)$ & $(0.52)$ & $(0.59)$ & $(0.60)$ & $(0.95)$ \\
\hline N time spells & 184 & 184 & 184 & 184 & 184 & 184 \\
\hline N rule births & 54 & 54 & 54 & 54 & 54 & 54 \\
\hline LR statistic & 6.96 & 7.91 & $12.59^{*}$ & 7.96 & 8.43 & $12.88^{*}$ \\
\hline Log likelihood & -650.80 & -649.61 & -647.27 & -649.58 & -649.34 & -647.12 \\
\hline Robust sta & & & & \\
\hline & & & & & & \\
\hline
\end{tabular}

Robust standard errors are reported in parentheses.

$* p<0.1, * * p<0.05, * * * p<0.01$. 
As expected, we find a significant positive relationship between rule birth and rule death events. In line with the findings of March et al., ${ }^{49}$ the repeal of existing legal rules opens up problem space for the introduction of new rules. This rule dynamic, in turn, is reflected in the positive relationship between the two types of events. Table 2 also provides support for the rule birth density dependence hypothesis, as shown in Figure 3.

Figure 3 Rule birth and rule density

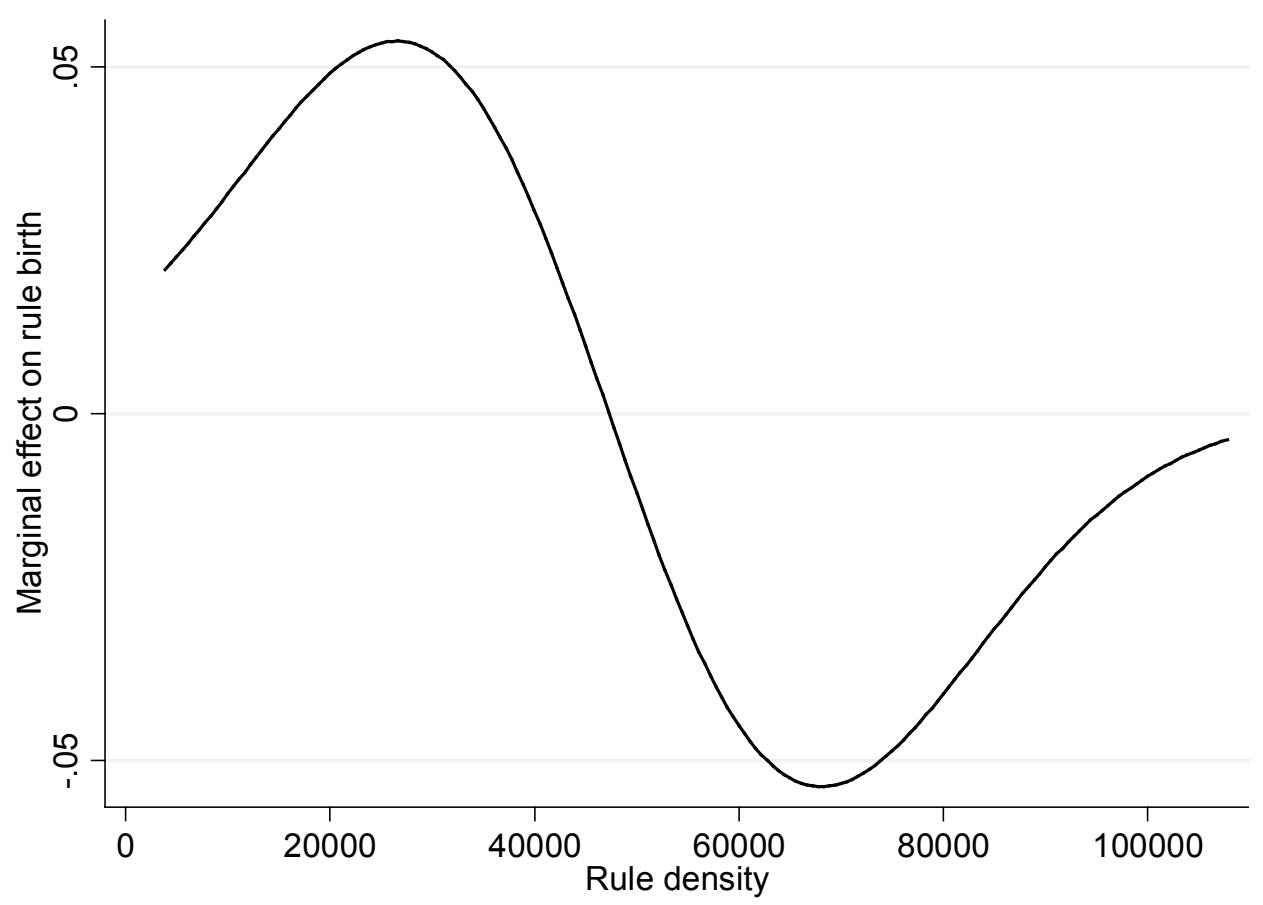

The estimated parameters for rule density $(\beta=0.11$ with $p<0.01)$ and rule density squared $(\beta=-1.16 \mathrm{e}-6$ with $p<0.01)$ have the expected opposite signs, and are both highly significant. Indeed, we find the predicted inverse U-shaped pattern, whereby low rule densities have a positive marginal effect on rule birth events. At higher density levels, rule density has a dampening effect on the introduction of new rules. Surprisingly, this dampening effect becomes weaker with rule densities of 70,000 words and more. Apparently, after reaching a certain threshold level, the dampening effect on rule birth caused by learning effects is partly cancelled out by increased demands for the introduction of new rules. Even so, the positive effect at low rule densities and the negative effect at high rule densities upon rule birth are as expected.

As a robustness check, we performed the analysis with lagged density variables. The density dependence result remains robust up to sixteen lags of the density variables (results are available from the authors upon request). All three control variables have the expected positive coefficients, but only the EU member states variable and court activity variable are significant in the full Model 6 at $p<0.1$ and $p<0.05$, respectively. Finally, there is a positive relationship between rule birth and rule increase changes, implying that events with a size increase effect on the rule stock are strongly correlated. With regard to rule death events, our density dependence hypothesis is not supported, as can be seen in Table 3 .

Whereas our theory would suggest a U-shaped relationship between rule death events and density, the coefficients of the density variables have the wrong signs, as shown in Figure 4.

49 March et al., above n. 11. 
Table 3

Regression results for rule death events

\begin{tabular}{|c|c|c|c|c|c|c|}
\hline Measures & Model 1 & Model 2 & Model 3 & Model 4 & Model 5 & Model 6 \\
\hline Rule increase change & $1.61 * * *$ & 0.64 & -0.06 & $2.23 *$ & 1.60 & 0.88 \\
\hline (variable divided by 1,000 ) & $(0.44)$ & $(1.00)$ & $(0.56)$ & $(1.15)$ & $(1.02)$ & $(1.49)$ \\
\hline Rule decrease change & 21.72 & 21.11 & 5.73 & -3.80 & -3.58 & 0.63 \\
\hline (variable divided by 1,000 ) & (13.88) & $(17.16)$ & $(6.95)$ & $(5.07)$ & $(4.10)$ & $(7.22)$ \\
\hline \multirow[t]{2}{*}{ EU enlargement } & 0.68 & -0.34 & $-1.64 *$ & & & \\
\hline & $(0.68)$ & $(0.89)$ & $(0.91)$ & & & \\
\hline \multirow[t]{2}{*}{ EU member states } & & & & $0.30 * * *$ & $0.29 * * *$ & $0.39 *$ \\
\hline & & & & $(0.08)$ & $(0.09)$ & $(0.21)$ \\
\hline \multirow[t]{2}{*}{ EU treaty } & $1.33^{*}$ & $1.59 * *$ & 0.25 & 1.03 & $1.42 * *$ & 1.00 \\
\hline & $(0.72)$ & $(0.76)$ & $(0.65)$ & $(0.66)$ & $(0.70)$ & $(0.68)$ \\
\hline \multirow[t]{2}{*}{ Court activity (lagged) } & $0.33 * * *$ & $0.30 * * *$ & $3.24 \mathrm{e}-3$ & $0.14 * *$ & 0.11 & 0.05 \\
\hline & $(0.09)$ & $(0.09)$ & $(0.07)$ & $(0.07)$ & $(0.07)$ & $(0.06)$ \\
\hline Rule birth & & $0.26^{*}$ & $0.23 * * *$ & & $0.22 *$ & $0.16^{*}$ \\
\hline (variable divided by 1,000 ) & & $(0.15)$ & $(0.08)$ & & $(0.13)$ & $(0.08)$ \\
\hline Rule density & & & $0.09 * *$ & & & $0.14 * * *$ \\
\hline (variable divided by 1,000 ) & & & $(0.04)$ & & & $(0.04)$ \\
\hline Rule density squared & & & $-4.69 e-7$ & & & $-1.62 \mathrm{e}-6^{* *}$ \\
\hline (variable divided by 1,000 ) & & & $(3.47 \mathrm{e}-7)$ & & & $(7.42 \mathrm{e}-7)$ \\
\hline \multirow[t]{2}{*}{ Constant } & $3.22 * * *$ & $3.13 * * *$ & $2.36 * * *$ & 0.58 & 0.46 & -1.58 \\
\hline & $(0.65)$ & $(0.73)$ & $(0.85)$ & $(1.03)$ & $(1.13)$ & $(2.24)$ \\
\hline $\mathrm{N}$ time spells & 184 & 184 & 184 & 184 & 184 & 184 \\
\hline $\mathrm{N}$ rule deaths & 35 & 35 & 35 & 35 & 35 & 35 \\
\hline LR statistic & $10.07 *$ & $11.04 *$ & $14.48^{* *}$ & $13.02 * *$ & $13.99^{* *}$ & $15.76^{* * *}$ \\
\hline Log likelihood & -425.67 & -425.18 & -423.46 & -424.19 & -423.71 & -422.82 \\
\hline
\end{tabular}

Robust standard errors are reported in parentheses.

$* p<0.1, * * p<0.05, * * * p<0.01$

The density variable is significant at $p<0.01$, whereas the density squared measure is significant at $\mathrm{p}<0.05$. This finding remains the same if the density variables are lagged (results are available from the authors upon request). Thus, according to our results, rule death events show an ecological pattern comparable to that of rule birth events, albeit with smaller marginal effects. This finding implies that the standard U-shaped relationship between death events and density does not seem to hold for our population of legal rules. We believe that this unexpected pattern can largely be attributed to the infrequent occurrence of rule death events in general. For example, March et al. find only limited rule repeal events at Stanford University, ${ }^{50}$ while van Witteloostuijn and de Jong encounter a similar lack of significant rule death events in Dutch higher education law. ${ }^{51}$ As shown in Table 1 , the average size of rule death events in our own sample is roughly half the size of average rule birth events. When rule death events do occur, they often coincide with the introduction of new rules, which explains the similar graphs in Figures 3 and 4.

Apparently, the processes of competition and legitimation, equated with learning theory and Weberian and post-Weberian theory concerning the ecology of law approach, have a different effect on legal rules compared to organisations when it comes to death events. This finding is in line with anecdotal evidence indicating that it is much harder to repeal an existing rule than it is to introduce a new one.

50 Id.

51 Van Witteloostuijn and de Jong (2010), above n. 12. 
Figure 4 Rule death and rule density

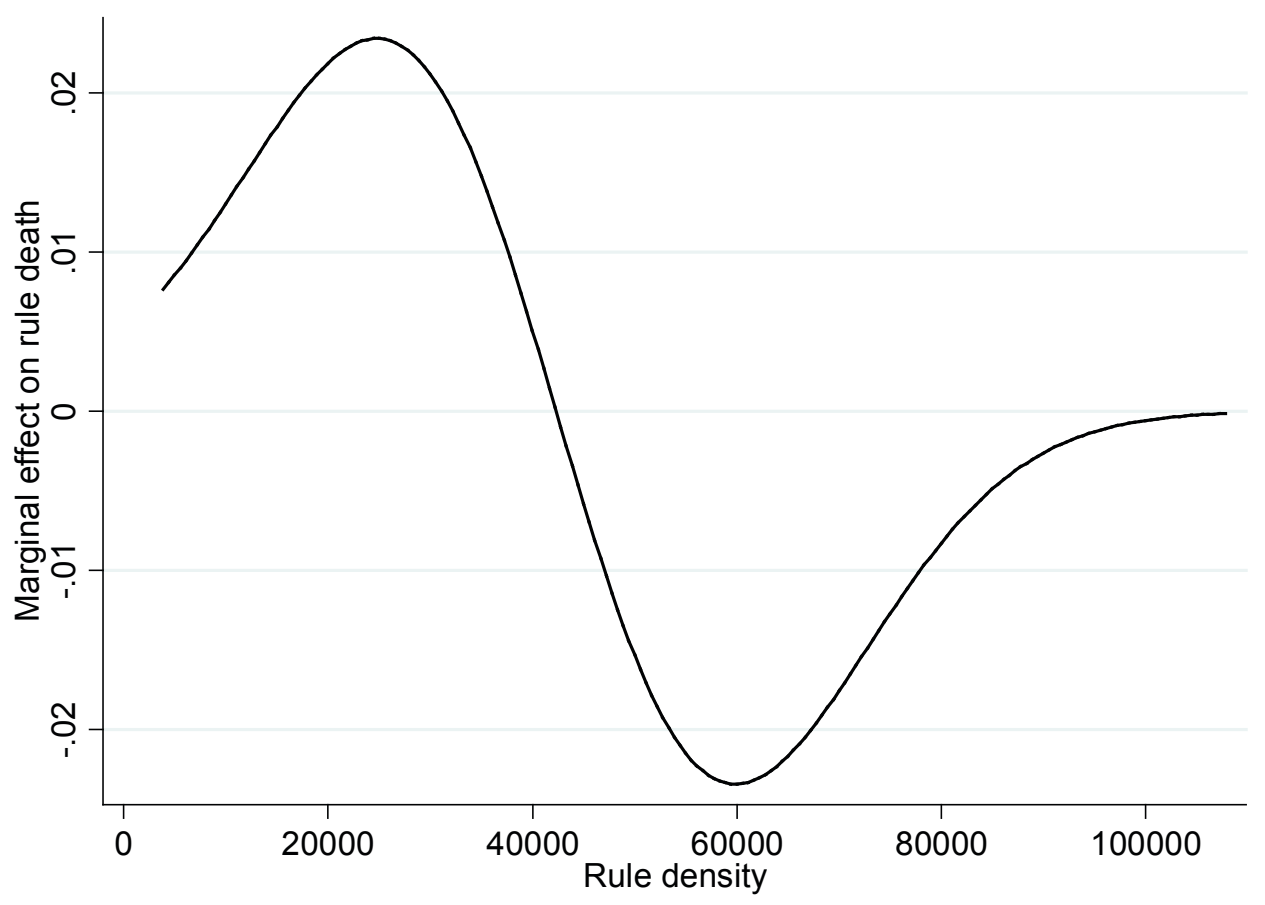

Once again, we find a significant positive relationship between rule death and rule birth events, comparable to the one in our rule birth analysis in terms of coefficient size and significance level. This finding provides further support for our prediction that rule birth and rule death events are strongly correlated since, to a certain extent, they occupy the same problem space. The EU treaty variable has a positive coefficient, but is not significant in the full Model 6 specification. Furthermore, the EU member states variable gives a significantly positive coefficient. However, this result does not appear to be very robust, as our alternative control for the number of EU member states, the EU enlargement variable, has a negative coefficient sign in Models 2 and 3. Finally, the court activity variable has the expected positive coefficient in all model specifications, although the coefficient size decreases and loses its significance in the full Model 6 specification. This is due to the inclusion of our density measures; if the court activity variable is excluded from the analysis, the results remain the same.

\section{Discussion and Conclusion}

In the present paper, we introduced an ecological approach in order to study the evolution of EU competition law. We argued that, apart from external drivers, there is also a population-specific internal dynamic that drives EU rule production. More specifically, we hypothesised that the processes of (post-)Weberian rule-breeding, on the one hand, and organisational learning, on the other hand, jointly result in (inverse) U-shaped density dependence relationships for rule birth and rule death events. Furthermore, we expected a positive relationship between rule birth and rule death events, and vice versa. In order to test these hypotheses, we manually counted the exact size of all rule birth, death and change events from the population of European competition law regulations for the period running from 1962 to 2008 .

Our descriptive results unambiguously show that the number of competition law rules has increased drastically since the mid-1980s. Furthermore, this growth has continued unabated to the present day, resulting in an ever-increasing rule stock of European competition law rules. Surprisingly, the introduction of the much-debated 
Regulation $1 / 2003,{ }^{52}$ which entered into force in 2004, has not altered this pattern of European competition rule evolution.

In order to test our density dependence hypotheses, as well as the positive relationship between rule death and rule birth events, we ran negative binomial regression analyses. After controlling for member state enlargement, EU treaty revision and court activity in our analyses, we found a significant hill-shaped relationship between rule density and rule births. This finding indicates that rule birth events occur more frequently at lower levels of rule density, although after reaching a certain density threshold rule birth events become less common. For the rule death and rule density relationship, we do not find the hypothesised U-shaped relationship. Instead, our results show a positive effect, indicating that rule death events increase with rule density. We attribute this finding to the fact that, in line with similar studies, the size of rule death activity is rather limited compared to rule birth events. As a result, the joint legitimation and competitive pressures of organisational learning are not (fully) reflected in rule death activity.

The model that we have presented in this paper only serves as a steppingstone toward a more thorough analysis of EU rule dynamics, which gives rise to at least four future research avenues. Firstly, we have only focused on policy output of one legal instrument within a single policy domain. Given the vital role of competition law within the common market, we would expect EU policy output in this domain to be a priori (relatively) high. Furthermore, the pattern of competition rules contained in regulations does not tell us anything about the evolution of other legal instruments, most notably directives and decisions. By extending our analysis to include other legal instruments, cross-density effects between these different instruments can be studied. For example, we might find that there is a positive relationship between, on the one hand, rule birth of legal rules contained in regulations and, on the other hand, rule birth of decisions.

Secondly, it could be fruitful to study cross-density effects between different policy domains at the EU level. An example would be to test whether increased legislative activity in one policy domain (e.g. agriculture) has an effect on legislative activity in another domain (e.g. competition law) - and if so, what type of effect. The joint analysis of different policy domains will not only allow for the study of group-wise correlations between different populations of legal rules, but can also provide a comprehensive picture of EU policy dynamics if the number of policy domains studied is sufficiently large (thus moving the ecological analysis beyond a case study of one particular policy domain).

Thirdly, institutional and rule-maker's characteristics should also be incorporated into our model in order to further enhance its explanatory power. Previous research by van Witteloostuijn and de Jong on the evolution of Dutch higher education law has shown that rule-maker characteristics have an effect on, for example, the propensity to introduce new rules. ${ }^{53}$ Likewise, the institutional setting in terms of, for example, legislative procedures, EU presidency and power composition within rule-producing bodies is also likely to affect the evolution of legal populations.

Fourthly, and finally, although we are able to infer that the number of competition rules has increased drastically, we cannot determine whether or not this increase is warranted. As mentioned before, the size of a legal document may have little correlation with its impact. In order to further improve our understanding of rule evolution, our quantitative approach could be extended to include qualitative information related to the effect of legal rules. The effect of legal rules, in turn, can be divided into (at least) two research questions: (1) What proportion of legal rules is applied in practice, versus rules that exist solely as 'laws on the books'?; and (2) What are the accompanying costs and benefits of legal rules? These research questions cannot be answered through quantitative data alone. Indeed, in order to analyse the overall impact of legal rules, input from policymakers and practitioners is, for example, also required.

52 Council Regulation (EC) No 1/2003, OJ 2003 L1.

53 Van Witteloostuijn and de Jong (2010), above n. 12. 